\title{
Degradation of skeletal mass in locally advanced oesophageal cancer between initial diagnosis and recurrence
}

\author{
Yacine Zouhry', Abdelkader Taibi², Sylvaine Durand-Fontanier², Tiffany Darbas' ${ }^{1}$, Geraud Forestier ${ }^{3}$, \\ Jacques Monteil ${ }^{4}$, Valérie Lebrun-Ly' ${ }^{1}$, Philippe Fayemendy, ${ }^{5,6}$, Sophie Leobon ${ }^{1}$, Pierre Jesus ${ }^{1}$ and Elise Deluche ${ }^{1 *}$
}

\begin{abstract}
Background: The prognostic value of a low skeletal mass index (SMI) has been investigated in locally advanced oesophageal (LAE) cancer at diagnosis. However, nothing is known about its evolution and clinical impact between initial diagnosis and recurrence.

Methods: A total of 89 patients treated for LAE cancer between January 2009 and December 2019 were included in this study. Computed tomography (CT) scans before treatment and at recurrence were evaluated. SMI and other body composition parameters were analysed by the L3 scan method.

Results: Participants were aged 66.0 (36.0-86) years. The incidence of low SMl increased by $12.3 \%$ between diagnosis and recurrence (70.7\% vs. 83.0\%, respectively) over a median follow-up of $16.9(1.7-101.6)$ months. Patients with high SMl at diagnosis showed loss of muscle mass $\left(58.0 \mathrm{vs} .55 .2 \mathrm{~cm}^{2} / \mathrm{m}^{2}\right.$, respectively; $\left.P<0.001\right)$ and decreased body mass index (BMI) (27.9 vs. $26.3 \mathrm{~kg} / \mathrm{m}^{2}$, respectively; $\left.P=0.05\right)$, but fat mass was increased $\left(68.9 \mathrm{vs} .72 .0 \mathrm{~cm}^{2} / \mathrm{m}^{2}\right.$, respectively; $P=0.01)$. Patients with low SMl at diagnosis showed no significant changes in body composition parameters and no improvement of SMI, even with nutritional support. Low SMI (hazard ratio [HR]: 1.8; 95\% confidence interval [CI]: 1.02-3.16) was an independent predictor $(P=0.041)$ of high nutritional risk index (HR: 1.79; 95\% Cl: 1.03-3.11; $P=0.039)$ at diagnosis.
\end{abstract}

Conclusions: The percentage of patients with a low SMI increased during follow-up. Our data suggest that an assessment of skeletal muscle parameters and nutrition support may be more useful in patients with a high SMI.

Keywords: Skeletal muscle mass, Oesophageal cancer, Nutrition, Outcome

\section{Background}

Cancer of the oesophagus is the 15th most common cause of cancer in Europe and accounts for $10 \%$ of all digestive cancers [1]. The gold standard of treatment for limited disease is endoscopic or surgical resection with neoadjuvant therapy, whereas radiochemotherapy

*Correspondence: elise.deluche@chu-limoges.fr

1 Medical Oncology Department, Limoges University Hospital, 2 avenue Martin Luther King, 87042 Limoges, France

Full list of author information is available at the end of the article is the gold standard in non-operable and non-resectable cases [2]. Despite some progress in the fields of surgical and medical oncology, the overall 5-year survival rate was slowly improved from $5 \%$ in the $1970 \mathrm{~s}$ to $20 \%$ in 2021. In details, the 5-year survival rate of patients with tumours localised only in the oesophagus is $47 \%, 25 \%$ in cases with disease that has spread to surrounding tissues or organs, and/or regional lymph nodes and $5 \%$ if it has spread to distant parts of the body [3]. Several prognostic factors have been studied for oesophageal cancer, including nutrition [4-6] and sarcopenia [7]. 
Sarcopenia is characterised by a loss of skeletal muscle mass (SMM), skeletal muscle strength and physical performance in quantitative and qualitative terms, as well as in anatomical and functional terms [8]. It was previously shown that assessment of SMM using the cross-sectional area of a single vertebral slice at lumbar L3 thanks computed tomography (CT) scan is well correlated with whole-body skeletal muscle volume. Prado et al. showed for the first time that muscle loss at the start of treatment, as assessed by L3 (CT scan), is a poor prognostic factor for solid tumours [9]. Pre-therapeutic sarcopenia is highly prevalent in cases of cancer and has major implications for patient outcomes [10]. It is important to note that in most studies, sarcopenia is considered to be the same as low skeletal muscle mass (SMM) even though their definition is somewhat different.

Some studies have reported associations between low SMM of patients with oesophageal cancer and oncological outcomes, such as survival [10-12], and suggested that low skeletal muscle mass could be an independent factor associated with pulmonary complications after curative oesophagectomy [11]. ITo our knowledge, most oesophageal cancer studies with longitudinal follow-up have been performed in the context of adjuvant or neoadjuvant therapy [13, 14]. There have been no such studies specifically following up for loss of muscle mass until recurrence. Most oesophageal cancer studies have evaluated patients at diagnosis $[7,10,11]$. One of the issues in the management of cancer patients is how long nutritional management lasts and how long it is effective. Often this is based on weight change alone, but this is likely to be insufficient. We hypothesised that sarcopenia worsens during the management of patients, particularly during a period when patients are less monitored because of post-treatment surveillance. However, we believe that improving sarcopenia is of great importance for patient with recurrent cancer, as they will be more likely to be able to receive adequate treatment for this recurrence[15]. This is why knowing the evolution of sarcopenia is important. Studies in other cancers have shown the importance of this evolution between "primary" and "secondary" sarcopenia [16].

In this study, we evaluated the change of skeletal muscle mass between the time of initial diagnosis and recurrence (local and/or distant) in patients with locally advanced oesophageal cancer. We also assessed the change of other body composition indices and the impact of body composition on morbidity (post-operative complications and length of hospital stay) and survival.

\section{Methods}

\section{Study population}

All consecutive patients treated for locally advanced oesophageal cancer diagnosed at Limoges University Hospital, Limoges, France, between January 2009 and December 2019 were initially included in this study. Among only patients $\geq 18$ years, with confirmed diagnosis of locally advanced oesophageal cancer (defined as stage II-III not eligible for primary surgical treatment), and who had a CT scan before treatment ( $<2$ months) and at recurrence were included. Surgical resection of residual tumour after chemoradiotherapy was permitted. The exclusion criteria were the concomitant presence of another neoplasm and a history of another primary cancer within the last 5 years, excluding in situ carcinomas of the cervix or previously treated basal cell carcinomas.

\section{Clinical and biological characteristics}

The following data were collected at the time of initial diagnosis and at recurrence: clinical and demographic characteristics, including age, sex, comorbidities (smoking and alcohol consumption) and World Health Organization (WHO) performance status (PS); pathological characteristics, such as TNM stage, histological type and location (classified as cervical and upper, middle, or lower third), surgical characteristics and complications; anthropometric measures of nutritional status, where body mass index (BMI) was used to define undernutrition $\left(\mathrm{BMI}<18.5 \mathrm{~kg} / \mathrm{m}^{2}\right)$, normal weight $\left(18.5-24.9 \mathrm{~kg} / \mathrm{m}^{2}\right)$, overweight $\left(25.0-29.9 \mathrm{~kg} / \mathrm{m}^{2}\right)$ and obesity $(\geq 30.0 \mathrm{~kg} /$ $\mathrm{m}^{2}$ ) in accordance with the WHO guidelines [17], and weight loss; nutritional management (oral nutritional supplements, enteral nutrition, parenteral nutrition); biological data (C-reactive protein and albumin levels) to calculate the nutritional risk index $(\mathrm{NRI} ; 1.519 \times$ serum albumin level $[\mathrm{g} / \mathrm{L}]+41.7 \times$ [weight at the beginning of treatment/baseline weight]), where patients were divided into three groups according to NRI score (no-risk group, NRI score $>97.5$; moderate risk group, NRI score 97.583.5-97.5; severe risk group, NRI score < 83.5) [18]; and treatment characteristics, including chemotherapy protocol and radiotherapy data (total dose and treatment duration).

\section{Analyses of body composition by CT}

Digital images were retrieved from the Picture Archiving and Communication System (Telemis version 4.7; Telemis SA, Louvain la Neuve, Belgium). All images were reviewed and analysed by a radiologist blinded to patient survival status using AW software (GE Healthcare, Waukesha, WI, USA), as described previously [19]. 
Skeletal muscle mass, visceral adipose tissue (VAT), subcutaneous adipose tissue (SAT) and infiltration intermuscular adipose tissue (IMAT) were identified and quantified from a single image at the third lumbar vertebra (L3) using the following Hounsfield unit (HU) thresholds: muscle, -29 to $150 \mathrm{HU}$; VAT, -150 to -50 HU; SAT and IMAT, -190 to $-30 \mathrm{HU}$. The skeletal mass index (SMI), VAT index, SAT index and IMAT index were calculated in $\mathrm{cm}^{2} / \mathrm{m}^{2}$ by tissue cross-sectional area $\left(\mathrm{cm}^{2}\right)$ normalised to square metres $\left(\mathrm{m}^{2}\right)$.

Skeletal muscle mass (skeletal muscle index, $\mathrm{cm}^{2} / \mathrm{m}^{2}$ ) and density (HU) at the level of the third lumbar vertebra were measured on contrast-enhanced CT images.

The estimated skeletal muscle mass and density for each subject, and the lower bound of the $90 \%$ prediction interval, were calculated.

The cut-offs for SMI were $38.5 \mathrm{~cm} 2 / \mathrm{m} 2$ for females and $52.4 \mathrm{~cm} 2 / \mathrm{m} 2$ for males $[9,20]$. Females SMI $<38.5 \mathrm{~cm} 2 /$ m2and men with SMI $52.4 \mathrm{~cm} 2 / \mathrm{m} 2$ were considered to have low SMI.

\section{Endpoints of the study}

The primary endpoint was the change of SMI between diagnosis and recurrence in patients with locally advanced oesophageal cancer.

The secondary endpoints were the change of SMI between diagnosis and recurrence according to the initial SMI, the change of other body composition parameters (VAT index, SAT index and IMAT index) and BMI status between initial diagnosis and recurrence, in the whole cohort and according to the initial SMI, and survival according to SMI (evaluated at diagnosis and recurrence).

\section{Statistical analysis}

Quantitative results are expressed as the mean \pm standard deviation (SD) or median (range), and qualitative results are expressed as numbers and percentages. Nominal variables were compared between the groups using the chi-square or Fisher's exact test, as appropriate. Means were compared using the non-parametric Mann-Whitney $U$ test for continuous variables and the Wilcoxon signed-rank test for paired tests. The paired $t$ test was used to examine correlations of changes between diagnosis and recurrence with changes in BMI, SMI and body composition.

Disease-free survival (DFS) was defined as the interval between surgery and the date of first recurrence. Overall survival (OS) was defined as the time between the date of diagnosis of metastatic disease and the date of death (any cause) or censored to the date of last contact. We used the Kaplan-Meier method to estimate OS and DFS, and the log-rank test to assess differences between SMI subgroups. The Cox proportional hazards model was used to identify prognostic factors of OS and DFS in the whole cohort, and to calculate hazard ratios (HRs) and 95\% confidence intervals (CIs). Variables with a $P$-value $<0.10$ in univariate analyses were included in multivariate analyses. The variables included in the model were age at diagnosis $(<$ or $\geq 65$ years), NRI ( $\leq$ or $>97.5$ ), first-line chemotherapy (yes or no) and SMI (low or high). $P<0.05$ was taken to indicate statistical significance. All data were analysed using StatView software (SAS Institute, Cary, NC, USA) and R software (v.3.5.1; The R Foundation for Statistical Computing, Vienna, Austria).

\section{Ethical approval}

Clinical data were collected in accordance with French bioethics laws regarding patient information and consent. Data collection and use were approved by the Limoges Hospital Ethics Committee (President, Dr. Terrier) (approval number 370-2020-26). All patients provided written informed consent for the collection and use of data from biological samples at the beginning of medical care. The use of retrospective and prospective data from the BRTS (regional solid tumour base) was also approved by the Ethics Committee (approval number 200-2016-14).

\section{Results}

\section{Patient characteristics at baseline and recurrence}

Among the total of 91 patients, baseline data were available for 89 and these patients constituted the whole cohort (eFigure 1). Tables 1 and 2 summarise the patient and tumour characteristics of the study cohort at diagnosis $(n=89)$ and recurrence $(n=47)$.

The median ages of the patients at initial cancer diagnosis and recurrence were $66.0(36.0-86.0)$ and 66.0 (36.0-84.0) years, respectively. The median BMI were 26.3 (17.0-52.9), 24.1 (14.9-47.7) and 23.8 (16.4-34.6) $\mathrm{kg} / \mathrm{m}^{2}$ before diagnosis, at diagnosis of cancer and at recurrence, respectively. At diagnosis, 10 patients (11.1\%) were undernourished, 40 (44.9\%) were normal weight, $30(33.8 \%)$ were overweight and $9(10.1 \%)$ were obese. The weight loss difference between before diagnosis and at diagnosis was $-8.0 \%[-1.2,-38.7]$, and that between diagnosis and recurrence was $-3.1 \%[-27.9,28.1]$.

All patients were on nutritional management and had access to personalised dietary counselling. There were no differences in nutritional management between the two groups $(P=0.4)$ (Tables 1 and 2 ).

Patients received these regimens of chemotherapy : FOLFOX, EOX or cisplatin. The major surgical procedure performed was a Lewis-Santy oesophagectomy. The median dose of radiotherapy was 50.4 Gy (50-60 Gy). 
Table 1 Patient and tumour characteristics at diagnosis in all cohorts and according to skeletal mass index

\begin{tabular}{|c|c|c|c|c|}
\hline Clinical and pathological parameters & $\begin{array}{l}\text { Total } \\
n=89\end{array}$ & $\begin{array}{l}\text { High SMI } \\
n=26(29.1 \%)\end{array}$ & $\begin{array}{l}\text { Low SMI } \\
n=63(70.7 \%)\end{array}$ & $P$-value \\
\hline Age (years), median (range) & $66.0(36.0-86.0)$ & $64.0(36.0-78.0)$ & $67.0(42.0-86.0)$ & 0.08 \\
\hline \multicolumn{5}{|l|}{ Sex } \\
\hline Male/female & $73(82.0) / 16(18.0)$ & $22(15.4) / 4(84.6)$ & $51(19.0) / 12(81.0)$ & 0.6 \\
\hline Smoking status & & & & 0.2 \\
\hline Yes & $33(37.0)$ & $10(38.5)$ & $23(36.5)$ & \\
\hline No & $13(14.6)$ & $6(23.0)$ & $7(11.1)$ & \\
\hline Ex-smoker & $43(48.4)$ & $10(38.5)$ & $33(52.4)$ & \\
\hline Alcohol drinker & & & & 0.1 \\
\hline Yes & $29(32.5)$ & $10(38.5)$ & $19(30.1)$ & \\
\hline No & $13(14.6)$ & $6(23.0)$ & $7(11.1)$ & \\
\hline Ex-alcohol drinker & $47(52.9)$ & $10(38.5)$ & $37(58.8)$ & \\
\hline Tumour histological subtype & & & & 0.03 \\
\hline Squamous cell carcinoma & $53(59.6)$ & $11(42.3)$ & $42(66.6)$ & \\
\hline Adenocarcinoma & $36(40.4)$ & $15(57.7)$ & $21(33.4)$ & \\
\hline Endobrachyoesophageal status & & & & 0.4 \\
\hline Yes/No & $13(14.6) / 76(85.4)$ & $5(19.2) / 21(80.8)$ & $8(12.7) / 55(87.3)$ & \\
\hline TNM Stage & & & & 0.1 \\
\hline$\|$ & $42(47.2)$ & $9(34.6)$ & $33(52.4)$ & \\
\hline III & $47(52.8)$ & $17(65.4)$ & $30(47.6)$ & \\
\hline Tumour location & & & & 0.4 \\
\hline Upper & $20(22.4)$ & $4(15.4)$ & $16(25.4)$ & \\
\hline Mean & $26(29.3)$ & $6(23.0)$ & $20(31.7)$ & \\
\hline Lower & $38(42.7)$ & $14(53.9)$ & $24(38.1)$ & \\
\hline More than two locations & $5(5.6)$ & $2(7.7)$ & $3(4.8)$ & \\
\hline Performance status & & & & 0.006 \\
\hline $0 / 1$ & $74(83.2)$ & $26(100.0)$ & $48(76.2)$ & \\
\hline $2 / 3$ & $15(16.8)$ & $0(0)$ & $15(23.8)$ & \\
\hline \multicolumn{5}{|l|}{ Nutritional parameters } \\
\hline \multicolumn{5}{|l|}{$\mathrm{BMI}\left(\mathrm{kg} / \mathrm{m}^{2}\right)$ before the cancer diagnosis } \\
\hline Median (range) & $26.3(17.0-52.9)$ & $28.8(21.2-52.9)$ & $25.1(17.0-37.6)$ & 0.0001 \\
\hline Underweight $(<18.5)$ & $1(1.1)$ & $0(0)$ & $1(1.6)$ & 0.006 \\
\hline Normal $(\geq 18.5<25.0)$ & $31(34.8)$ & $3(11.5)$ & $28(44.4)$ & \\
\hline Overweight ( $\geq 25.0<30.0$ ) & $18(20.2)$ & $10(38.5)$ & $8(12.7)$ & \\
\hline Obese $(\geq 30.0)$ & $39(43.9)$ & $13(50)$ & $26(41.3)$ & \\
\hline NRI at cancer diagnosis & & & & 0.6 \\
\hline$>97.5$ & $26(29.2)$ & $7(27.0)$ & $19(30.2)$ & \\
\hline $97.5-83.5$ & $41(46.0)$ & $11(42.3)$ & $30(47.6)$ & \\
\hline$<83.5$ & $22(24.8)$ & $8(30.7)$ & $19(22.2)$ & \\
\hline Albumin level (g/L) median (range) & $36.0(17.5-48.0)$ & $35.5(22.0-43.0)$ & $36.2(17.5-48.0)$ & 0.3 \\
\hline C-reactive protein, median (range) & $9.5(1.0-113.0)$ & $9.0(1.0-96.0)$ & $12(1.0-113.0)$ & 0.9 \\
\hline \multicolumn{5}{|l|}{$\mathrm{BMI}\left(\mathrm{kg} / \mathrm{m}^{2}\right)$ at cancer diagnosis } \\
\hline Median (range) & $24.1(14.9-47.7)$ & $27.9(20.9-47.7)$ & $22.6(14.9-37.2)$ & $<0.0001$ \\
\hline Underweight $(<18.5)$ & $10(11.1)$ & $0(0)$ & $10(15.9)$ & 0.0008 \\
\hline Normal $(\geq 18.5<25.0)$ & $40(44.9)$ & $8(30.7)$ & $32(50.8)$ & \\
\hline Overweight $(\geq 25.0<30.0$ ) & $30(33.8)$ & $11(42.3)$ & $19(30.2)$ & \\
\hline Obese $(\geq 30.0)$ & $9(10.1)$ & $7(27.0)$ & $2(3.1)$ & \\
\hline Weight loss (\%) median (range) & $8.0(-1.2-38.7)$ & $6.5(0-27.0)$ & $9.0(-1.2-38.7)$ & 0.2 \\
\hline
\end{tabular}


Table 1 (continued)

\begin{tabular}{|c|c|c|c|c|}
\hline Clinical and pathological parameters & $\begin{array}{l}\text { Total } \\
n=89\end{array}$ & $\begin{array}{l}\text { High SMI } \\
n=26(29.1 \%)\end{array}$ & $\begin{array}{l}\text { Low SMI } \\
n=63(70.7 \%)\end{array}$ & $P$-value \\
\hline Special nutritional management & & & & 0.4 \\
\hline Oral nutritional supplements & $19(21.3)$ & $7(27.0)$ & $12(19.0)$ & \\
\hline Enteral nutrition & $66(74.1)$ & $17(65.3)$ & $49(77.7)$ & \\
\hline Parenteral nutrition + enteral nutrition & $4(4.5)$ & $2(7.7)$ & $2(3.1)$ & \\
\hline Current therapies, $n(\%)$ & & & & 0.3 \\
\hline Chemotherapy & $22(24.7)$ & $8(30.7)$ & $14(22.2)$ & \\
\hline Radiotherapy & $10(11.2)$ & $1(3.9)$ & $9(14.3)$ & \\
\hline Radiochemotherapy & $57(64.1)$ & $17(65.4)$ & $40(63.5)$ & \\
\hline Surgery (yes) & $19(21.4)$ & $8(30.7)$ & $11(17.4)$ & 0.1 \\
\hline Complications & $14(73.6)$ & $6(75.0)$ & $8(72.7)$ & 0.9 \\
\hline Respiratory complications & $10(52.6)$ & $5(62.5)$ & $5(45.4)$ & 0.4 \\
\hline Length of hospital stay (days) & $28.0(14.0-60.0)$ & $24.0(14.0-44.0)$ & $29.5(19.0-60.0)$ & 0.4 \\
\hline Relapse & & & & 0.04 \\
\hline No & $42(47.2)$ & $12(46.1)$ & $30(47.6)$ & \\
\hline Local relapse & $23(25.8)$ & $3(11.5)$ & $20(31.7)$ & \\
\hline Metastatic relapse & $24(27.0)$ & $11(42.3)$ & $13(20.6)$ & \\
\hline
\end{tabular}

BMI: body mass index; NRI: nutritional risk index; SMI: skeletal muscle index

\section{Changes in SMI and body composition parameters during follow-up}

In the whole cohort, the proportion of patients with a low SMI was $70.7 \%$ at diagnosis and $83.0 \%$ at recurrence, representing an increase of $12.3 \%$. At recurrence, only four patients maintained a high SMI, while 10 maintained a low one. Nineteen patients remained at a low SMI and four changed to a high SMI (Table 3). The rates of SMI are shown in Table 3.

SAT and IMAT remained stable. VAT increased between diagnosis and recurrence $\left(52.2\right.$ and $58.6 \mathrm{~cm}^{2} / \mathrm{m}^{2}$, respectively; $P<0.001$ ), whereas BMI decreased during the follow-up period $\left(24.1\right.$ and $23.8 \mathrm{~kg} / \mathrm{m}^{2}$, respectively; $P=0.04$ ) (Table 4).

\section{Patient characteristics and body composition parameters according to SMI}

The characteristics of the patients according to SMI (high vs. low), at diagnosis and at recurrence, are listed in Table 1 and 2. Significant differences in PS scores were observed between the groups, with $100 \%$ of high SMI patients having a "good" PS score compared to $76.2 \%$ of low SMI patients $(P=0.006)$.

In the low SMI group at diagnosis, all body composition parameters remained stable between diagnosis and recurrence (Table 4). Between diagnosis and recurrence, the group with a high SMI at diagnosis showed significant decreases in muscle mass $\left(58.0\right.$ and $55.2 \mathrm{~cm}^{2} / \mathrm{m}^{2}$, respectively; $P<0.001)$ and BMI $\left(27.9\right.$ and $26.3 \mathrm{~kg} / \mathrm{m}^{2}$, respectively; $P=0.05$ ), whereas their fat mass increased significantly $\left(68.9\right.$ and $72.0 \quad \mathrm{~cm}^{2} / \mathrm{m}^{2}$, respectively; $P=0.01$ ) (Table 4).

\section{Multivariate analyses of DFS and OS according to SMI at diagnosis}

The median follow-up of the cohort was 16.9 (1.7-101.6) months. OS and DFS were assessed according to SMI at diagnosis.

Among patients with a low SMI at diagnosis, 33 (52\%) showed disease recurrence after treatment, with a median time to recurrence of 14.2 months, whereas 14 (53\%) patients with a high SMI showed disease recurrence after a median of 18.8 months. In univariate analysis, no differences in DFS were observed between the two groups (Fig. 1a) $(P=0.51)$.

The median OS of the cohort was 21.3 (95\% CI: 14.8$27.9)$ months. Fifty-two patients $(82.5 \%)$ in the low SMI group died compared to $17(65.3 \%)$ in the high SMI group.

As shown in Fig. 1b, the median OS was 15.8 (95\% CI: 12.2-25.3) months in the low SMI group and 31.7 (95\% CI: 22.1-NA) months in the high SMI group $(P=0.023)$. In multivariate analyses, a low SMI (HR: 1.80; 95\% CI: 1.02-3.16; $P=0.0417$ ) and NRI $\leq 97.5$ (HR: $1.79 ; 95 \%$ CI: $1.03-3.11 ; P=0.04)$ were positively associated with mortality risk (Table 5 ). 
Table 2 Patient and tumour characteristics at recurrence in all cohorts and according to skeletal mass index

\begin{tabular}{|c|c|c|c|c|c|}
\hline & $\begin{array}{l}\text { Total at relapse } \\
n=47\end{array}$ & $\begin{array}{l}\text { High SMId-High SMIr } \\
n=4\end{array}$ & $\begin{array}{l}\text { High SMId-low SMIr } \\
n=10\end{array}$ & $\begin{array}{l}\text { Low SMId-Low SMIr } \\
n=29\end{array}$ & $\begin{array}{l}\text { Low SMId-High SMIr } \\
n=4\end{array}$ \\
\hline Age (years), median (range) & $\begin{array}{l}66.0 \\
(36.0-84.0)\end{array}$ & $\begin{array}{l}74.0 \\
(63.0-79.0)\end{array}$ & $\begin{array}{l}62.0 \\
(37.0-69.0)\end{array}$ & $\begin{array}{l}68.0 \\
(43.0-85.0)\end{array}$ & $\begin{array}{l}72.0 \\
(67.0-77.0)\end{array}$ \\
\hline \multicolumn{6}{|l|}{ Sex } \\
\hline Male/female & $39(83.0) / 8(17.0)$ & $2(50) / 2(50)$ & $0(0) / 10(100)$ & 5()$/ 24()$ & $10 / 30$ \\
\hline \multicolumn{6}{|l|}{ Performance status } \\
\hline $0 / 1$ & $37(78.7)$ & $4(100)$ & $10(100)$ & $22(75.8)$ & $3(75)$ \\
\hline $2 / 3$ & $10(21.2)$ & $0(0)$ & $0(0)$ & $7(24.2)$ & $1(25)$ \\
\hline \multicolumn{6}{|l|}{$N R 1^{*}$} \\
\hline$>97.5$ & $7(17.0)$ & $1(25)$ & $0(0)$ & $6(24.0)$ & $0(0)$ \\
\hline $97.5-83.5$ & $18(44.0)$ & $2(50)$ & $3(33.4)$ & $8(32.0)$ & $2(66.6)$ \\
\hline$<83.5$ & $16(39.0)$ & $1(25)$ & $6(66.6)$ & $11(44.0)$ & $1(33.4)$ \\
\hline Albumin levels $(\mathrm{g} / \mathrm{L})^{*}$ & $34.0(18.0-44.5)$ & $34.8(22.7-40.2)$ & $26.5(20.2-40.0)$ & $35.0(18.4-44.5)$ & $35.6(18.0-39.0)$ \\
\hline C-reactive protein ${ }^{* *}$ & $14.0(1.0-254.0)$ & $8.5(3.0-14.0)$ & $26.0(1.0-199.0)$ & $13.0(1.0-178.0)$ & $20.5(3.0-254.0)$ \\
\hline \multicolumn{6}{|l|}{ BMI $\left(\mathrm{kg} / \mathrm{m}^{2}\right)$} \\
\hline $\begin{array}{l}\text { Median } \\
\text { (min-max) }\end{array}$ & $23.8(16.4-34.6)$ & $30.3(26.1-34.6)$ & $24.6(19.7-29.8)$ & $23.1(16.4-30.8)$ & $24.9(21.7-26.6)$ \\
\hline $\begin{array}{l}\text { Underweight } \\
(<18.5)\end{array}$ & $5(10.6)$ & $0(0)$ & $0(0)$ & $5(17.2)$ & $0(0)$ \\
\hline $\begin{array}{l}\text { Normal } \\
(\geq 18.5<25.0)\end{array}$ & $22(46.8)$ & $0(0)$ & $6(60)$ & $14(48.2)$ & $2(50)$ \\
\hline $\begin{array}{l}\text { Overweight } \\
(\geq 25.0<30.0)\end{array}$ & $3(6.4)$ & $2(50)$ & $0(0)$ & $1(3.4)$ & $0(0)$ \\
\hline Obese $(\geq 30.0)$ & $17(36.2)$ & $2(50)$ & $4(40)$ & $9(31.0)$ & $2(50)$ \\
\hline \multicolumn{6}{|c|}{ Special nutritional management*** } \\
\hline Oral nutritional supplements & $22(48.9)$ & $1(25)$ & $5(55.5)$ & $13(46.4)$ & $3(75)$ \\
\hline Enteral nutrition & $21(46.7)$ & $3(75)$ & $3(33.3)$ & $14(50)$ & $1(25)$ \\
\hline Parenteral nutrition & $2(4.4)$ & $0(0)$ & $1(11.2)$ & $1(3.7)$ & $0(0)$ \\
\hline
\end{tabular}

*6 missing data

**10 missing data

***2 missing data

BMI: body mass index; d: at diagnosis, r: at relapse; NRI: nutritional risk index; SMI: skeletal muscle index

Table 3 Changes of skeletal muscle index between diagnosis and recurrence

\begin{tabular}{lll}
\hline At initial diagnosis & At relapse & \\
\cline { 2 - 3 } & High SMI & Low SMI \\
\hline High SMI & $n=4$ & $n=10$ \\
& SMI at diagnosis: $58.0(42.6-75.2)$ & SMl at diagnosis: $58.2(53.0-62.6)$ \\
Low SMI & SMl at relapse: $52.8(39.4-78.2))$ & SMl at relapse: $47.7(41.6-52.3)$ \\
& $n=4$ & $n=29$ \\
Total & SMl at diagnosis: $44.9(35.8-51.0)$ & SMl at diagnosis: $42.8(32.8-51.8)$ \\
\hline
\end{tabular}

SMI: skeletal muscle index

\section{Multivariate analyses of DFS and OS according to SMI} at recurrence

OS and DFS were assessed according to SMI at recurrence. No differences in DFS were observed between the groups over time, including after analysing the variation in SMI during follow-up (eFigure 2). SMI was not an independent negative predictor of OS in multivariate analyses. 
Table 4 Changes in body composition between diagnosis and recurrence

\begin{tabular}{|c|c|c|c|c|c|c|c|c|c|}
\hline & Whole cohort & & & Initial high SM & group & & Initial low SMI & group & \\
\hline & At diagnosis & At relapse & $P$-value* & At diagnosis & At relapse & $P$-value* & At diagnosis & At relapse & $P$-value ${ }^{a}$ \\
\hline $\begin{array}{l}\mathrm{SMI}\left(\mathrm{cm}^{2} / \mathrm{m}^{2}\right) \\
\text { median (range) }\end{array}$ & $\begin{array}{l}44.9(25.3- \\
75.2)\end{array}$ & $\begin{array}{l}45.4(30.8- \\
78.2)\end{array}$ & 0.08 & $\begin{array}{l}58.0(42.6- \\
75.2)\end{array}$ & $\begin{array}{l}55.2(39.4- \\
78.2)\end{array}$ & $<0.001$ & $\begin{array}{l}42.3(25.3- \\
51.8)\end{array}$ & $\begin{array}{l}44.5(30.8- \\
52.3)\end{array}$ & 0.71 \\
\hline $\begin{array}{l}\text { VAT index } \\
\left(\mathrm{cm}^{2} / \mathrm{m}^{2}\right) \\
\text { median (range) }\end{array}$ & $\begin{array}{l}52.2 \\
(1.4-164.4)\end{array}$ & $\begin{array}{l}58.6 \\
(3.7-160.7)\end{array}$ & $<0.001$ & $\begin{array}{l}68.9 \\
(6.9-159.8)\end{array}$ & $\begin{array}{l}72.0(16.4- \\
95.6)\end{array}$ & 0.014 & $\begin{array}{l}43.7 \\
(1.4-164.4)\end{array}$ & $\begin{array}{l}56.7 \\
(3.7-160.7)\end{array}$ & 0.82 \\
\hline $\begin{array}{l}\text { SAT index } \\
\left(\mathrm{cm}^{2} / \mathrm{m}^{2}\right) \\
\text { median (range) }\end{array}$ & $44.5(0.6-61.8)$ & $\begin{array}{l}43.7(5.09- \\
198.4)\end{array}$ & 0.8 & $23.6(2.4-55.3)$ & $\begin{array}{l}71.1(21.2- \\
198.4)\end{array}$ & 0.77 & $15.6(0.6-61.8)$ & $\begin{array}{l}42.7(5.09- \\
101.9)\end{array}$ & 0.54 \\
\hline $\begin{array}{l}\text { IMAT index } \\
\left(\mathrm{cm}^{2} / \mathrm{m}^{2}\right), \\
\text { median (range) }\end{array}$ & $0.12(0.0-0.5)$ & $0.09(0.02-0.5)$ & 0.9 & $0.09(0.1-0.5)$ & $0.09(0.02-0.5)$ & 0.60 & $0.11(0.0-0.5)$ & $0.10(0.02-0.4)$ & 0.74 \\
\hline BMI $\left(\mathrm{kg} / \mathrm{m}^{2}\right)$ & $\begin{array}{l}24.1(14.9- \\
47.7)\end{array}$ & $\begin{array}{l}23.8(16.4- \\
34.6)\end{array}$ & 0.04 & $\begin{array}{l}27.9(20.9- \\
47.7)\end{array}$ & $\begin{array}{l}26.3(21.7- \\
34.6)\end{array}$ & 0.05 & $\begin{array}{l}22.6(14.9- \\
37.2)\end{array}$ & $\begin{array}{l}23.5(16.4- \\
30.8)\end{array}$ & 0.21 \\
\hline
\end{tabular}

IMAT: infiltration inter-muscular adipose tissue; SAT: subcutaneous adipose tissue; SMI: skeletal muscle index; VAT: visceral adipose tissue

${ }^{a}$ paired $t$ test

\section{Discussion}

This study was performed to examine whether baseline skeletal muscle mass indices change over the follow-up period in patients with locally advanced oesophageal cancer. To our knowledge, this is the first study to demonstrate a change in SMI in this population between diagnosis and recurrence. We showed an increase of $12.3 \%$ in the low SMI group, indicating degradation of skeletal muscle mass.

The prevalence of a low SMI at diagnosis in the present study was $70.7 \%$, consistent with previously reported rates of $25.5-86.0 \%$ [21-32] and validating our initial population selection. The prevalence of a low SMI increased to $83.0 \%$ at recurrence. Body composition remained stable in the low SMI group, whereas the high SMI group showed a decrease in muscle mass and increase in fat mass. This decrease in skeletal muscle mass was greater than would be expected naturally (approximately $1.4 \%$ per year due to physiological aging) [33].

Few studies have evaluated changes in body composition during follow-up of oesophageal cancer patients, and data have only been collected in the context of adjuvant and neoadjuvant therapy $[13,14]$. The prevalence of sarcopenia in oesophageal cancer was reported to increase during neoadjuvant treatment [34], consistent with our findings. Regarding other types of cancer, two studies observed long-term loss of SMI in patients with medullary thyroid carcinoma or renal carcinoma receiving treatment (6-9 months) [35, 36], while an adjuvant breast cancer study observed an increase in total body fat and decreases in fat-free mass and lean soft tissue, but no changes in body weight [37].

One possible explanation for the increased prevalence of low SMI, even with nutritional support, is a lack of exercise training to enhance muscle strength and function. Sarcopenia has been a topic of recent interest in the context of physical activity. It would be useful to obtain data on changes of muscle strength (e.g., results of the handgrip test) in these patients, particularly those who have maintained or gained lean mass. Exercise rehabilitation has been investigated in cancer patients, including those with breast cancer, and was shown to have a positive effect on muscle strength [38, 39]; similar findings were also reported in oesophago-gastric cancer survivors [40]. However, the RESTORE program (exercise

Table 5 Univariate and multivariate analyses of body composition parameters associated with overall survival

\begin{tabular}{|c|c|c|c|c|}
\hline & \multicolumn{4}{|l|}{ Overall survival } \\
\hline & \multicolumn{2}{|l|}{ Univariate } & \multicolumn{2}{|l|}{ Multivariate } \\
\hline & $\mathrm{HR}(95 \% \mathrm{Cl})$ & $P$-value & $\mathrm{HR}(95 \% \mathrm{Cl})$ & $P$-value \\
\hline Age at diagnosis (< 65 years) & $0.5953[0.364-0.9736]$ & 0.0388 & 0.6853 [0.4089-1.1485] & 0.1515 \\
\hline $\mathrm{NRI}(\leq 97.5)$ & $1.6996[0.9797-2.949]$ & 0.0592 & $1.7865[1.0270-3.1080]$ & 0.0399 \\
\hline Chemotherapy (yes) & $0.4667[0.2265-0.9617]$ & 0.0388 & 0.6122 [0.2840-1.3197] & 0.2105 \\
\hline Low SMI & $1.8830[1.084-3.272]$ & 0.0248 & 1.7973 [1.0224-3.1590] & 0.0417 \\
\hline
\end{tabular}

NRI: nutritional risk index; SMI: skeletal muscle index 


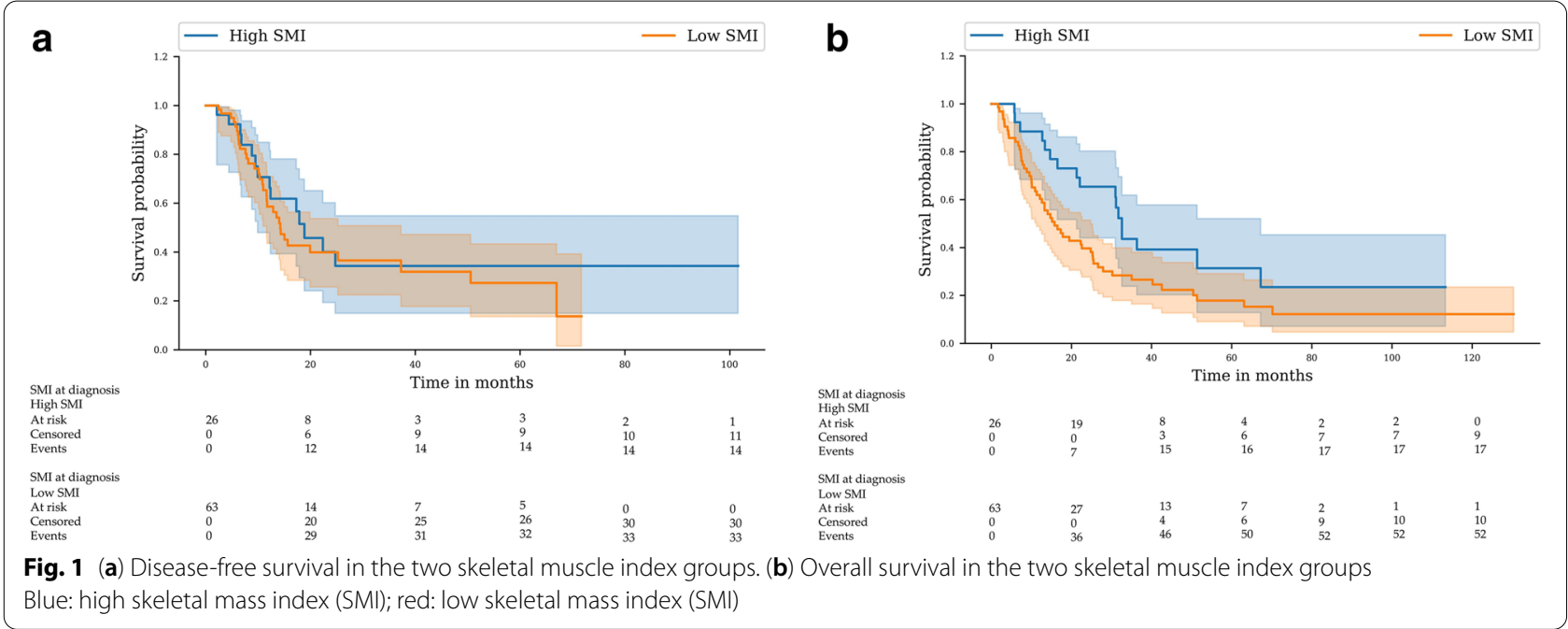

training, dietary counselling and multidisciplinary education) showed that body composition remained stable even after targeted training [41]. Similarly, Guinan et al. reported that despite maintenance of functional capacity and activities, the muscle mass and strength of patients $(n=28)$ declined between pre- and post-neoadjuvant therapy [42].

In addition to various factors such as age, PS, disease stage and comorbidities, a low SMI could be another useful parameter to incorporate into the clinical decisionmaking process. The present study showed that a low SMI at diagnosis was an independent prognostic factor. Three large systematic reviews and meta-analyses of preoperative sarcopenia in patients with oesophageal cancer concluded that sarcopenia is associated with poorer OS, as determined by CT in patients from European centres, regardless of whether the patients received preoperative treatment or the definition of sarcopenia was used [7, 10, 11]. A systematic review and meta-analysis reported a significant increase in overall morbidity (relative risk [RR]: 1.16; 95\% CI: 1.01-1.33) in patients with sarcopenia [43], and another study reported poorer long-term outcomes after oesophagectomy in sarcopenic patients (HR: 1.70; 95\% CI: 1.33-2.17) [7]. Deng et al. reported that patients with sarcopenia had significantly lower 3-year (51.6\% and 65.4\%, respectively) and 5-year OS rates (41.2\% and $52.2 \%$, respectively) than those without sarcopenia [11].

The present study could not conclusively determine the role of sarcopenia in post-operative complications but it was not the main scope of this project. Most previous studies reported that pre-operative sarcopenia, as assessed by $\mathrm{CT}$, was not associated with significantly higher rates of overall post-operative complications or overall mortality $[7,10,11]$. More precisely, an association between pre-operative sarcopenia and post-oesophagectomy pulmonary complications has been reported; a higher incidence of post-operative pulmonary complications (RR: 2.03; 95\% CI: 1.32-3.11, $P=0.001)$ was observed in sarcopenia patients after oesophagectomy [7], while Papaconstantinou et al. observed an increase in the rate of respiratory complications (RR: 1.64; 95\% CI: 1.21-2.22) among such patients [43]. However, a recent meta-analysis of eight studies involving 1,488 patients suggested that sarcopenia does not affect the rate of post-operative complications, including respiratory complications, in patients undergoing oesophagectomy for oesophageal cancer [44].

The last question we aimed to answer was whether it is necessary to monitor the SMI [45]. We showed that only the initial SMI had an impact on outcome $[7,10,11]$. $\mathrm{CT}$ is often used to evaluate the whole body before treatment; measuring the SMI using this modality is clinically convenient, with no requirement to determine changes in SMI during follow-up. Although body mass index at the time of recurrence was not associated with survival outcomes in our patients, Measuring grip strength or walk test is simple and inexpensive and may be relevant for early detection of sarcopenia and modification of our management [46].

This study had some limitations. First, it was a retrospective investigation conducted at a single institution. One of the limitations of this retrospective study is the heterogeneity of management between 2009 and 2019 due to the variation in recommendations. These data could better analyzed on a prospective clinical trial. Second, we evaluated only low SMI and not sarcopenia, as defined by the European Working Group on Sarcopenia in Older People (EWGSOP), because of the nature of the study [8]. However, this study fits perfectly with a multidisciplinary healthcare approach, in which screening for 
low skeletal mass should involve a nutritionist once CT has been performed. Third, the cut-off values for diagnosis of sarcopenia remain controversial and could vary according to the population of interest. The Asian Working Group for Sarcopenia (AWGS) published specific consensus guidelines to define sarcopenia in this population $[47,48]$. In this study, we used the cut-off proposed by Prado et al. [9]. However, no cut-off value has been validated in a prospective study, particularly for oesophageal cancer. Due to the confusion between sarcopenia and low SMI in the initial studies, the most frequently used cut-offs historically are those of Prado et al. who initially referred to sarcopenia and not SMI.

\section{Conclusion}

At diagnosis, SMI was an independent prognostic factor in patients with local advanced oesophageal cancer. Low SMI was shown to be associated with poor survival outcomes at diagnosis. Evaluation of SMI at recurrence may not change the outcome of oesophageal cancer. It appears essential to accurately evaluate sarcopenia to develop multimodal interventions integrating nutritional support and physical exercise specifically for oesophageal cancer patients, to improve muscle mass and function. The change of SMI emphasises the need to increase nutritional intake and physical activity in this group of patients over the long term. Today, the methods for detecting sarcopenia are improving, but we do not yet know how to correct it in order to improve patient care.

\section{Abbreviations}

BMI: body mass index; Cl: confidence interval; CT: computed tomography; DFS: disease-free survival; HR: hazard ratio; HU: Hounsfield units; IMAT: infiltration inter-muscular adipose tissue; NRI: nutritional risk index; OS: overall survival; PS: performance status; SAT: subcutaneous adipose tissue; SMI: skeletal muscle index; VAT: visceral adipose tissue.

\section{Supplementary Information}

The online version contains supplementary material available at https://doi. org/10.1186/s12885-021-09037-3.

\section{Additional file 1: eFigure 1. Study flowchart.}

Additional file 2: eFigure 2. a) Disease-free survival in the two skeletal muscle index groups at relapse. b) Overall survival in the two skeletal muscle index groups at relapse.

\section{Acknowledgements}

We thank Textcheck for their assistance in editing the language of this manuscript. The English in this document has been checked by at least two professional editors, both native speakers of English.

For a certificate, please see: http://www.textcheck.com/certificate/tZEdFb.

\section{Authors' contributions}

$Y Z, G F, E D$ and SL acquired the data. SL performed the statistical analyses.

$Y Z, E D$ and SL analysed the data. ED and SL supervised the work. All authors contributed to the manuscript, critically revised the manuscript and approved the final version.

Funding sources

None.

Availability of data and materials

Data are available from the corresponding author upon reasonable.

\section{Declarations}

Ethics approval and consent to participate

This study was approved by the Limoges Hospital Ethics Committee (President, Dr. Terrier) (approval number 370-2020-26).

\section{Consent for publication}

Not Applicable.

\section{Competing interests}

The authors declare that they have no conflicts of interest in relation to this study

\section{Author details}

${ }^{1}$ Medical Oncology Department, Limoges University Hospital, 2 avenue Martin Luther King, 87042 Limoges, France. ${ }^{2}$ Digestive Surgery Department, Limoges University Hospital, 2 avenue Martin Luther King, 87042 Limoges, France. ${ }^{3}$ Neuroradiology Department, Limoges University Hospital, 2 avenue Martin Luther King, 87042 Limoges, France. ${ }^{4}$ Nuclear Medicine Department, Limoges University Hospital, 2 avenue Martin Luther King, 87042 Limoges, France. ${ }^{5}$ Nutrition Unit, Limoges University Hospital, 2 avenue Martin Luther King, 87042 Limoges, France. ${ }^{6}$ Tropical Neuroepidemiology Institute GEIST, INSERM, U1094, 33 rue François Mitterrand, 87032 Limoges, France.

Received: 29 September 2021 Accepted: 19 November 2021

Published online: 07 December 2021

\section{References}

1. Ferlay J, Colombet M, Soerjomataram I, Dyba T, Randi G, Bettio M, et al. Cancer incidence and mortality patterns in Europe: Estimates for 40 countries and 25 major cancers in 2018. Eur J Cancer. 2018;103:356-87.

2. Lordick F, Mariette C, Haustermans K, Obermannová R, Arnold D, ESMO Guidelines Committee. Oesophageal cancer: ESMO Clinical Practice Guidelines for diagnosis, treatment and follow-up. Ann Oncol. 2016;27 suppl 5:v50-7.

3. Cancer of the Esophagus - Cancer Stat Facts. SEER. https://seer.cancer. gov/statfacts/html/esoph.html. Accessed 17 Dec 2020.

4. Sakanaka K, Fujii K, Ishida Y, Miyamoto S, Horimatsu T, Muto M, et al. Nutritional and clinical outcomes of chemoradiotherapy for clinical T1NOMO esophageal carcinoma. Cancer Manag Res. 2019;11:3623-30.

5. Di Fiore A, Lecleire S, Gangloff A, Rigal O, Benyoucef A, Blondin V, et al. Impact of nutritional parameter variations during definitive chemoradiotherapy in locally advanced oesophageal cancer. Dig Liver Dis. 2014;46:270-5.

6. Gao H, Feng H-M, Li B, Lin J-P, Yang J-B, Zhu D-J, et al. Impact of high body mass index on surgical outcomes and long-term survival among patients undergoing esophagectomy: A meta-analysis. Medicine. 2018;97.

7. Boshier PR, Heneghan R, Markar SR, Baracos VE, Low DE. Assessment of body composition and sarcopenia in patients with esophageal cancer: a systematic review and meta-analysis. Dis Esophagus. 2018;31.

8. Cruz-Jentoft AJ, Bahat G, Bauer J, Boirie Y, Bruyère O, Cederholm T, et al. Sarcopenia: revised European consensus on definition and diagnosis. Age Ageing. 2019:48:16-31.

9. Prado CMM, Lieffers JR, McCargar $\sqcup$, Reiman T, Sawyer MB, Martin L, et al. Prevalence and clinical implications of sarcopenic obesity in patients with solid tumours of the respiratory and gastrointestinal tracts: a populationbased study. Lancet Oncol. 2008;9:629-35. 
10. Pamoukdjian F, Bouillet T, Lévy V, Soussan M, Zelek L, Paillaud E. Prevalence and predictive value of pre-therapeutic sarcopenia in cancer patients: A systematic review. Clin Nutrit. 2018;37:1101-13.

11. Deng H-Y, Zha P, Peng L, Hou L, Huang K-L, Li X-Y. Preoperative sarcopenia is a predictor of poor prognosis of esophageal cancer after esophagectomy: a comprehensive systematic review and meta-analysis. Dis Esophagus Off J Int Soc Dis Esophagus. 2019;32:doy115.

12. Anjanappa M, Corden M, Green A, Roberts D, Hoskin P, McWilliam A, et al. Sarcopenia in cancer: Risking more than muscle loss. Tech Innovations Patient Support Radiation Oncol. 2020;16:50-7.

13. Yoon HG, Oh D, Ahn YC, Noh JM, Pyo H, Cho WK, et al. Prognostic Impact of Sarcopenia and Skeletal Muscle Loss During Neoadjuvant Chemoradiotherapy in Esophageal Cancer. Cancers (Basel). 2020;12:E925.

14. Kawakita Y, Motoyama S, Sato Y, Wakita A, Nagaki Y, Imai K, et al. Decreases in the Psoas Muscle Index Correlate More Strongly with Survival than Other Prognostic Markers in Esophageal Cancer After Neoadjuvant Chemoradiotherapy Plus Esophagectomy. World J Surg. 2020;44:1559-68.

15. Prado CM, Baracos VE, McCargar $\amalg$, Reiman T, Mourtzakis M, Tonkin K, et al. Sarcopenia as a determinant of chemotherapy toxicity and time to tumor progression in metastatic breast cancer patients receiving capecitabine treatment. Clin Cancer Res. 2009;15:2920-6.

16. Takiguchi K, Furuya S, Sudo M, Saito R, Yamamoto A, Ashizawa N, et al. Prognostic effect of sarcopenia in colorectal cancer recurrence. Nutrition. 2021:91-92:111362.

17. World Health Organization (WHO). Body mass index - BMI. 2018. http:// www.euro.who.int/en/health-topics/disease-prevention/nutrition/a-healt hy-lifestyle/body-mass-index-bmi. Accessed 9 Jul 2018.

18. Clavier J-B, Antoni D, Atlani D, Ben Abdelghani M, Schumacher C, Dufour $P$, et al. Baseline nutritional status is prognostic factor after definitive radiochemotherapy for esophageal cancer. Dis Esophagus. 2014;27:560-7.

19. Mourtzakis M, Prado CMM, Lieffers JR, Reiman T, McCargar LJ, Baracos VE. A practical and precise approach to quantification of body composition in cancer patients using computed tomography images acquired during routine care. Appl Physiol Nutr Metab. 2008;33:997-1006.

20. Takahashi K, Watanabe M, Kozuki R, Toihata T, Okamura A, Imamura Y, et al. Prognostic Significance of Skeletal Muscle Loss During Early Postoperative Period in Elderly Patients with Esophageal Cancer. Ann Surg Oncol. 2019:26:3727-35.

21. Anandavadivelan P, Brismar TB, Nilsson M, Johar AM, Martin L. Sarcopenic obesity: A probable risk factor for dose limiting toxicity during neo-adjuvant chemotherapy in oesophageal cancer patients. Clinical Nutrition. 2016;35:724-30.

22. Elliott JA, Doyle SL, Murphy CF, King S, Guinan EM, Beddy P, et al. Sarcopenia: Prevalence, and Impact on Operative and Oncologic Outcomes in the Multimodal Management of Locally Advanced Esophageal Cancer. Ann Surg. 2017;266:822-30.

23. Grotenhuis BA, Shapiro J, van Adrichem S, de Vries M, Koek M, Wijnhoven BPL, et al. Sarcopenia/Muscle Mass is not a Prognostic Factor for Shortand Long-Term Outcome After Esophagectomy for Cancer. World J Surg. 2016;40:2698-704.

24. Järvinen T, Ilonen I, Kauppi J, Salo J, Räsänen J. Loss of skeletal muscle mass during neoadjuvant treatments correlates with worse prognosis in esophageal cancer: a retrospective cohort study. World J Surg Oncol. 2018;16:27.

25. Mallet R, Modzelewski R, Lequesne J, Mihailescu S, Decazes P, Auvray H, et al. Prognostic value of sarcopenia in patients treated by Radiochemotherapy for locally advanced oesophageal cancer. Radiat Oncol. 2020;15:116.

26. Mayanagi S, Tsubosa Y, Omae K, Niihara M, Uchida T, Tsushima T, et al. Negative Impact of Skeletal Muscle Wasting After Neoadjuvant Chemotherapy Followed by Surgery on Survival for Patients with Thoracic Esophageal Cancer. Ann Surg Oncol. 2017;24:3741-7.

27. Nakashima Y, Saeki H, Nakanishi R, Sugiyama M, Kurashige J, Oki E, et al. Assessment of Sarcopenia as a Predictor of Poor Outcomes After Esophagectomy in Elderly Patients With Esophageal Cancer. Ann Surg. 2018;267:1100-4.

28. Nishigori T, Okabe H, Tanaka E, Tsunoda S, Hisamori S, Sakai Y. Sarcopenia as a predictor of pulmonary complications after esophagectomy for thoracic esophageal cancer. J Surg Oncol. 2016;113:678-84.

29. Onishi S, Tajika M, Tanaka T, Hirayama Y, Hara K, Mizuno N, et al. Prognostic Significance of Sarcopenia in Patients with Unresectable Advanced Esophageal Cancer. J Clin Med. 2019;8:1647.

30. Siegal SR, Dolan JP, Dewey EN, Guimaraes AR, Tieu BH, Schipper PH, et al. Sarcopenia is not associated with morbidity, mortality, or recurrence after esophagectomy for cancer. Am J Surg. 2018;215:813-7.
31. Tan BHL, Brammer K, Randhawa N, Welch NT, Parsons SL, James EJ, et al. Sarcopenia is associated with toxicity in patients undergoing neo-adjuvant chemotherapy for oesophago-gastric cancer. Eur J Surg Oncol. 2015;41:333-8.

32. Yip C, Goh V, Davies A, Gossage J, Mitchell-Hay R, Hynes O, et al. Assessment of sarcopenia and changes in body composition after neoadjuvant chemotherapy and associations with clinical outcomes in oesophageal cancer. Eur Radiol. 2014:24:998-1005.

33. Frontera WR, Hughes VA, Fielding RA, Fiatarone MA, Evans WJ, Roubenoff R. Aging of skeletal muscle: a 12-yr longitudinal study. J Appl Physiol (1985). 2000;88:1321-6.

34. Panje CM, Höng L, Hayoz S, Baracos VE, Herrmann E, Garcia Schüler H, et al. Skeletal muscle mass correlates with increased toxicity during neoadjuvant radiochemotherapy in locally advanced esophageal cancer: A SAKK 75/08 substudy. Radiat Oncol Lond Engl. 2019;14:166.

35. Massicotte M-H, Borget I, Broutin S, Baracos VE, Leboulleux S, Baudin E, et al. Body Composition Variation and Impact of Low Skeletal Muscle Mass in Patients With Advanced Medullary Thyroid Carcinoma Treated With Vandetanib: Results From a Placebo-Controlled Study. J Clin Endocrinol Metabolism. 2013;98:2401-8.

36. Antoun S, Baracos VE, Birdsell L, Escudier B, Sawyer MB. Low body mass index and sarcopenia associated with dose-limiting toxicity of sorafenib in patients with renal cell carcinoma. Ann Oncol Off J Eur Soc Med Oncol. 2010;21:1594-8.

37. Freedman RJ, Aziz N, Albanes D, Hartman T, Danforth D, Hill S, et al. Weight and Body Composition Changes during and after Adjuvant Chemotherapy in Women with Breast Cancer. J Clin Endocrinol Metabolism. 2004;89:2248-53.

38. Adams SC, Segal RJ, MCKenzie DC, Vallerand JR, Morielli AR, Mackey JR, et al. Impact of resistance and aerobic exercise on sarcopenia and dynapenia in breast cancer patients receiving adjuvant chemotherapy: a multicenter randomized controlled trial. Breast Cancer Res Treat. 2016;158:497-507.

39. Klassen O, Schmidt ME, Ulrich CM, Schneeweiss A, Potthoff K, Steindorf $\mathrm{K}$, et al. Muscle strength in breast cancer patients receiving different treatment regimes. J Cachexia Sarcopenia Muscle. 2017;8:305-16.

40. O'Connor L, Smyth E, Bennett AE, Smith V, O'Neill L, Reynolds JV, et al. Identifying outcomes reported in exercise interventions in oesophagogastric cancer survivors: a systematic review. BMC Cancer. 2021;21:586.

41. O'Neill LM, Guinan E, Doyle SL, Bennett AE, Murphy C, Elliott JA, et al. The RESTORE Randomized Controlled Trial: Impact of a Multidisciplinary Rehabilitative Program on Cardiorespiratory Fitness in Esophagogastric cancer Survivorship. Ann Surg. 2018;268:747-55.

42. Guinan EM, Doyle SL, Bennett AE, O'Neill L, Gannon J, Elliott JA, et al. Sarcopenia during neoadjuvant therapy for oesophageal cancer: characterising the impact on muscle strength and physical performance. Support Care Cancer. 2018;26:1569-76.

43. Papaconstantinou D, Vretakakou K, Paspala A, Misiakos EP, Charalampopoulos A, Nastos C, et al. The impact of preoperative sarcopenia on postoperative complications following esophagectomy for esophageal neoplasia: a systematic review and meta-analysis. Dis Esophagus. 2020;33.

44. Schizas D, Frountzas M, Lidoriki I, Spartalis E, Toutouzas K, Dimitroulis $D$, et al. Sarcopenia does not affect postoperative complication rates in oesophageal cancer surgery: a systematic review and meta-analysis. Ann R Coll Surg Engl. 2020;102:120-32.

45. Cotogni P, Monge T, Fadda M, De Francesco A. Bioelectrical impedance analysis for monitoring cancer patients receiving chemotherapy and home parenteral nutrition. BMC Cancer. 2018;18:990.

46. Meerkerk CDA, Chargi N, Jong PA de, Bos F van den, Bree R de. Sarcopenia measured with handgrip strength and skeletal muscle mass to assess frailty in older patients with head and neck cancer. J Geriatric Oncol. 2021;12:434-40.

47. Chen L-K, Liu L-K, Woo J, Assantachai P, Auyeung T-W, Bahyah KS, et al. Sarcopenia in Asia: consensus report of the Asian Working Group for Sarcopenia. J Am Med Dir Assoc. 2014;15:95-101.

48. Chen L-K, Lee W-J, Peng L-N, Liu L-K, Arai H, Akishita M, et al. Recent Advances in Sarcopenia Research in Asia: 2016 Update From the Asian Working Group for Sarcopenia. J Am Med Dir Assoc. 2016;17:767.e1-7.

\section{Publisher's Note}

Springer Nature remains neutral with regard to jurisdictional claims in published maps and institutional affiliations. 